\title{
Computational Investigation of Flow in a Centrifugal Impeller with Chamfered Blade Tips: Effects of Stage Loading and Tip Clearance
}

\author{
Nekkanti Sitaram ${ }^{1,}$, , Vanamala Ushasri ${ }^{2}$ \\ ${ }^{1}$ Department of Mechanical Engineering, IIT Madras, Chennai, India \\ ${ }^{2}$ Department of Mechanical Engineering, Osmania University, Hyderabad, India \\ Email address: \\ nsitaram.iitm@gmail.com (N. Sitaram), vushasri@rediff.com (V. Ushasri) \\ ${ }^{*}$ Corresponding author
}

To cite this article:

Nekkanti Sitaram, Vanamala Ushasri. Computational Investigation of Flow in a Centrifugal Impeller with Chamfered Blade Tips: Effects of Stage Loading and Tip Clearance. International Journal of Fluid Mechanics \& Thermal Sciences. Special Issue: Fluid Mechanics \& Thermal Sciences in Turbomachines. Vol. 6, No. 3, 2020, pp. 79-88. doi: 10.11648/j.ijfmts.20200603.12

Received: May 18, 2020; Accepted: July 13, 2020; Published: August 13, 2020

\begin{abstract}
The objective of the present investigation is to examine the possibility of performance improvement, improvement of the exit flow uniformity and desensitization of the tip clearance effects on the performance of a low speed centrifugal impeller. Computational investigations using a commercial CFD software are undertaken. Six configurations of blade tips are investigated. They are square tip (Basic), tip chamfered on pressure surface (P1 and P2), tip chamfered on suction surface (P1 and P2) and tip chamfered on pressure and suction surfaces (PS1). Computations are carried out with optimized multiblock grids for these six configurations at five flow coefficients, namely 0.28 and 0.34 (below design flow coefficient), 0.42 (design flow coefficient) and 0.48 and 0.52 (above design flow coefficient) and at three values of tip clearance, viz., $1 \%$ (small value), $2 \%$ (nominal value) and 5\% (large value) of the blade exit height. From the investigations, it is found that the impeller with the chamfer on suction surface shows small improvement in performance. In addition this configuration has minimum tip clearance sensitivity. A decrease in the chamfer on suction surface further may improve the impeller performance. A maximum percentage of $0.18 \%$ improvement in the total pressure coefficient is obtained at $5 \%$ tip clearance and a flow coefficient of 0.52 for configuration S2. However chamfer on the pressure surface deteriorates the impeller performance.
\end{abstract}

Keywords: Centrifugal Impeller, Chamfered Blade Tip, Computational Fluid Dynamics, Performance Improvement

\section{Introduction}

The centrifugal compressor is widely used in process industries, turbochargers, small gas turbine engines, etc. The inherent advantages of centrifugal compressor are high pressure ratio per stage, compactness, light weight design, low mass flow applications, reasonable efficiency, large surge margin and low cost. The flow field in the centrifugal impeller is influenced by the complex curvature of the impeller blades, the rotational forces, and clearance between the rotating impeller and stationary casing. To achieve any improvement of flow field in this region, the flow phenomenon in the passage is to be analysed and well understood. The blade loading near the tip of the blade is high and the leakage losses in this region are significant. The change in the geometry in the tip region alters the flow field in this region. Computational investigation of flow field in a centrifugal impeller with chamfered blade tips is carried out in the present paper, to examine the possibility of performance improvement, improvement of the exit flow uniformity and desensitization of the tip clearance effects.

The curvature of centrifugal compressor impeller blade channels, along with strong rotational forces and tip clearance between the rotating impeller and stationary casing generates secondary flows in unshrouded impellers that transport low momentum fluid into the mainstream of the impeller passage. Boundary layer separation on casing and suction surface of the impeller blade and secondary flow in the impeller passage lead to the formation of wake on the suction surface near casing. The losses and flow distortions in the impeller passage are 
mainly due to the wake formation. The tip clearance flow interacts with the low momentum fluid resulting in highly three-dimensional complex flow pattern both inside the impeller blade passage and impeller exit.

However, small improvement in the flow uniformity reduces the total pressure loss due to mixing in the vaneless space of the diffuser. Johnson and Moore [1] noticed convection of low energy fluid by the secondary flow, and formation of wake in the casing/suction side corner region of the passage. Senoo [2] and Sitaram and Sridhara [3] had carried out comprehensive reviews on pressure losses and flow field distortion induced by tip clearance flows in centrifugal compressors. The tip clearance between the impeller blades and casing can be varied by radial, axial or both radial and axial movement of the casing. Hayami [4] carried out experiments on tip clearance effects on a transonic centrifugal compressor. The high pressure ratio centrifugal compressor is tested with three kinds of distribution of tip clearance along the impeller shroud. The distribution was changed by reforming the shroud casing in the inducer portion, or by the axial movement of the shroud casing relative to the impeller, or by a combination of two methods. He found that the radial movement of the shroud reduces the flow range; the combined clearance reduces the efficiency more than two times the case of the axial movement of the shroud casing. In many cases, clearance is changed by axial movement of the casing as it is the most practical way and also the loss in efficiency is small. Pampreen [5] reported a drop of $0.3 \%$ in efficiency for $1 \%$ increase in the relative tip clearance. Sitaram and Pandey [6] carried out performance tests and rotor exit surveys at three tip clearances and six flow coefficients and reported similar findings. The effect of tip leakage has been studied on centrifugal compressor with tip clearance by Farge et al. [7]. They reported that with tip clearance, significant changes in the secondary velocities alter the size and position of the passage wake. Senoo and Ishida [8] reported that in case of impellers with radial blades, the blade loading is proportional to the flow rate and the leakage loss is increased with the flow rate. Ubaldi et al. [9] concluded that turbulence kinetic energy is very high on the pressure side of the blade wake, where the jet has originated, and is lower on the suction side. Hathaway and Wood [10] used three-dimensional viscous code in their computational investigation of NASA low speed centrifugal compressor flow field. They concluded that increasing grid density in the tip gap by a factor of 6.5 resulted in no difference in predicted tip clearance overall flow nor in the chord wise distribution of the clearance flow. A fairly coarse grid used seems perfectly adequate.

The blade loading at the tip of the blade is high, and the change in the geometry of the tip may change the tip leakage behavior and its associated losses. Ishida et al. [11] have conducted performance tests using unshrouded centrifugal impeller blades for three blade tip configurations, namely round edge (R-type), sharp square edge (S-type), and edge with a short end plate on the pressure surface side of the impeller blade tip (E-type). The rate of reduction in impeller efficiency and in the total pressure becomes smaller in the following order: R-type, S-type, and E-type. This improvement is attributed to the increased contraction coefficient of leakage flow. Sitaram and Swamy [12] also carried out similar investigations with partial shroud on the pressure surface side of the impeller blade tip of the present centrifugal impeller and reported similar findings.

Senthil and Sitaram [13] experimentally studied the performance of a low speed centrifugal compressor by means of squealer tips and found that the squealer tip improve the compressor performance. They observed increase in energy coefficient and efficiency with squealer tips on pressure or suction surface. Recently Da Soghe et al. [14] carried out numerical studies on the effects of various tip recessed geometries at two values of tip clearances on the performance of a transonic centrifugal compressor. Based on the results, further computations were carried out with a single rim tip squealer geometry, which had shown performance improvements for all the computed conditions. Jung et al. [15] carried out steady computations for three different blade tip geometries over the whole operating range. A flat tip blade was used as a baseline case to assess two different recessed blade geometries. It was found that recessed blade tip designs improved the total-to-total pressure ratio and efficiency over whole operating range. The recessed tips were also effective in reducing the tip leakage flow. Recently Mahajan et al. [16] had carried out computations on a transonic centrifugal compressor with a winglet on the suction side of the impeller blade near its tip. They had shown that the isentropic efficiency of the impeller with winglet was improved compared to the reference impeller.

Extensive work is carried out on the effect of tip geometry modification on flow properties and heat transfer properties for axial flow turbines. But such studies on centrifugal compressors are limited and there is a vast scope for further research. In the present paper, computational study is conducted to analyse the effects of tip geometry in the centrifugal impeller by chamfering blade tip. Both winglet or partial shroud and squealer tip are made of extremely thin material. Hence they are structurally weak when used in high speed centrifugal compressors. Chamfer of the tip does not adversely weaken the impeller blade. Thus chamfering of the blade tip is a better option if the improvement in the pressure rise is atleast comparable to that obtained with winglet, partial shroud and squealer tip.

Hence the present investigation is undertaken to computationally study the effect of chamfer of the tip of a low speed centrifugal impeller on the performance improvement and de-sensitization of tip clearance effects using CFD. The objective is to use impeller tip chamfering as a mean to improve the performance of the impeller in terms of increased pressure rise, increased efficiency, and increased stability and operating range. It is also examined if chamfering will improve the uniformity of exit flow and desensitize the tip clearance effects. The computations are carried out using a commercial CFD software, namely TASCflow3d. The computations are carried out at five flow 
coefficients, above, near and below design flow coefficients at three values (nominal, normal and large) of tip clearance. The computations are carried out at six impeller tip configurations, namely basic square tip configuration, with small and large chamfers on the suction and pressure surfaces and chamfer on both suction and pressure surfaces.

\section{Description of the Research Work}

\subsection{Impeller Details}

Computational study of the flow behavior in a low speed centrifugal impeller with tip clearance and chamfered tips was carried out in the present paper. The design details of the impeller used in the present investigation are given in Table 1.

Table 1. Design details of the impeller.

\begin{tabular}{ll}
\hline Rotor speed, $\mathrm{N}$ & $2000 \mathrm{rpm}$ \\
Design volume flow, $\mathrm{V}$ & $1.12 \mathrm{~m}^{3} / \mathrm{s}$ \\
Design pressure rise, $\Delta \mathrm{p}$ & $300 \mathrm{~mm}$ \\
Shape number, $\mathrm{N}_{\mathrm{sh}}=\mathrm{N}(\mathrm{V})^{0.5} / 60(\mathrm{~W})^{0.75}$ & 0.09 \\
Inducer hub diameter, $\mathrm{d}_{1 \mathrm{~h}}$ & $160 \mathrm{~mm}$ \\
Blade angle at inducer hub, $\beta_{1 \mathrm{~h}}$ & $53^{\circ}$ \\
Inducer tip diameter, $\mathrm{d}_{1 \mathrm{t}}$ & $300 \mathrm{~mm}$ \\
Blade angle at inducer tip, $\beta_{1 \mathrm{t}}$ & $35^{\circ}$ \\
Impeller tip diameter, $\mathrm{d}_{2}$ & $500 \mathrm{~mm}$ \\
Blade angle at exit, $\beta_{2}$ & $90^{\circ}$ \\
Blade height at the exit, $\mathrm{h}_{2}$ & $34.7 \mathrm{~mm}$ \\
No. of impeller blades, $\mathrm{N}_{\mathrm{b}}$ & 16 \\
Thickness of the blade, $\mathrm{t}$ & $3 \mathrm{~mm}$ \\
Vaneless diffuser exit diameter, $\mathrm{D}_{4}$ & $600 \mathrm{~mm}$ \\
All angles are with respect to the tangential direction. & \\
\hline
\end{tabular}

\subsection{Computational Details}

Centrifugal impeller with the above specifications is shown in Figure 1. Taking periodic boundary conditions, a single passage of the impeller with inlet at $50 \mathrm{~mm}$ ahead of the impeller and outlet at a distance of $35 \mathrm{~mm}$ downstream of impeller is modeled. The passage considered is half the blade spacing on either side of the blade. Computational domain of single passage along with boundary conditions is shown in Figure 2. For the centrifugal impeller geometry modeling, BladeGen software is used. In the present study the blade coordinates at twelve spanwise locations are considered for obtaining good geometric definition of the blade. Casing is designed with a clearance of $0.35 \mathrm{~mm}$ corresponding to $1 \%$ of the relative tip clearance throughout the blade length. Three values of tip clearance of $1 \%, 2 \%$ and $5 \%$ of blade exit height are obtained by moving the casing axially. By the axial adjustment of the casing, the clearance near the leading edge of the inducer changes very little. Tip clearance of $1 \%$ may be considered as the minimum possible value, $2 \%$ as the normal clearance and $5 \%$ as the large clearance for this compressor.

For the grid generation TurboGrid software is used. Structured multi block grid with 11 blocks consisting of a total 527,201 elements (optimum grid for 2\% clearance and 0.42 flow coefficient) is used for the $1 \%, 2 \%$ and $5 \%$ clearance models. The tip clearance region over the blade is modeled with 3 blocks with a total of 129,297 elements. For obtaining finer details in the boundary layers, four blocks of fine grid around the blade is used for all cases. The multi grid block topology used for centrifugal compressor main passage at blade mid span is shown in Figures 3 and 4. Total pressure with boundary layer profile is used for inlet boundary condition. Mass flow rate is given at outlet. The mass flow rate is calculated from the chosen flow coefficient. As single passage with half the pitch on either side of the blade is solved, periodic boundary conditions are employed on the sides of the domain. Rotating frame of reference is employed for the entire domain. For the stationary casing, no slip condition with absolute zero velocity is used. The impeller blade is rotating with an angular velocity of the domain. The hub up to the blade trailing edge is rotating with an angular velocity of the domain. The hub from the trailing edge of the blade to the exit of the domain is given the boundary condition as stationary wall. Standard k- $\varepsilon$ turbulence model is used for the closure. Inlet turbulence intensity is taken as $2 \%$. TASCflow $3 \mathrm{~d}$ software is used for obtaining the solution.

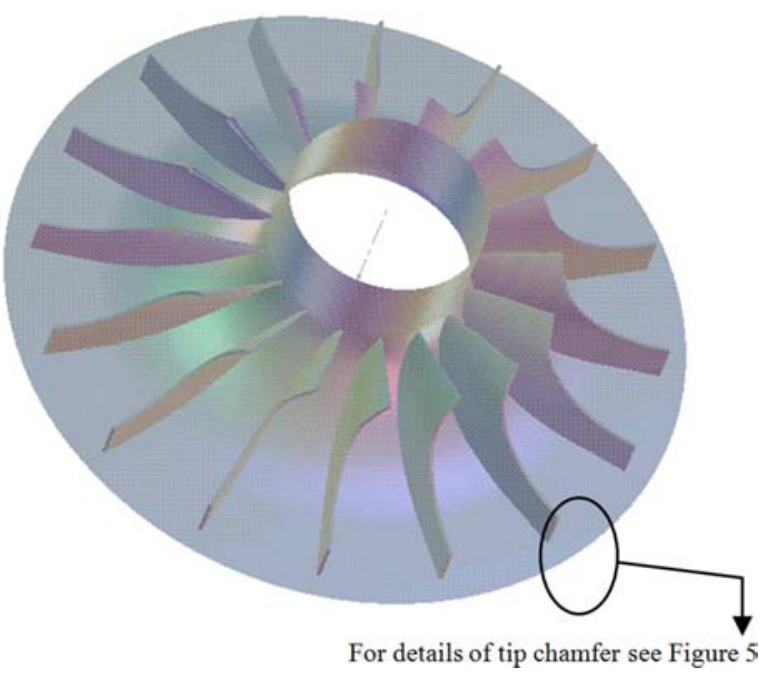

Figure 1. Three dimensional view of the centrifugal impeller.

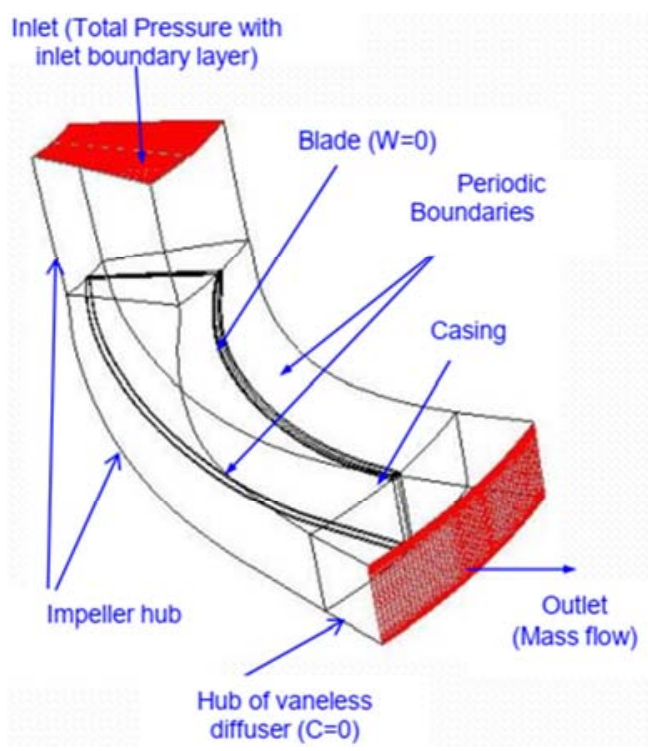

Figure 2. Computational domain of single passage. 


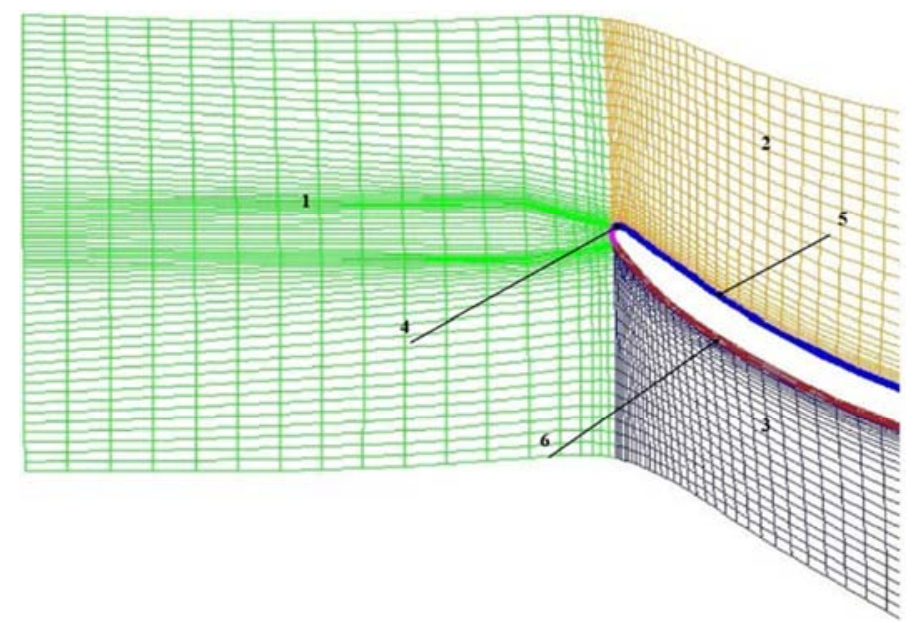

Figure 3. Passage grid block structure near leading edge at blade mid span.

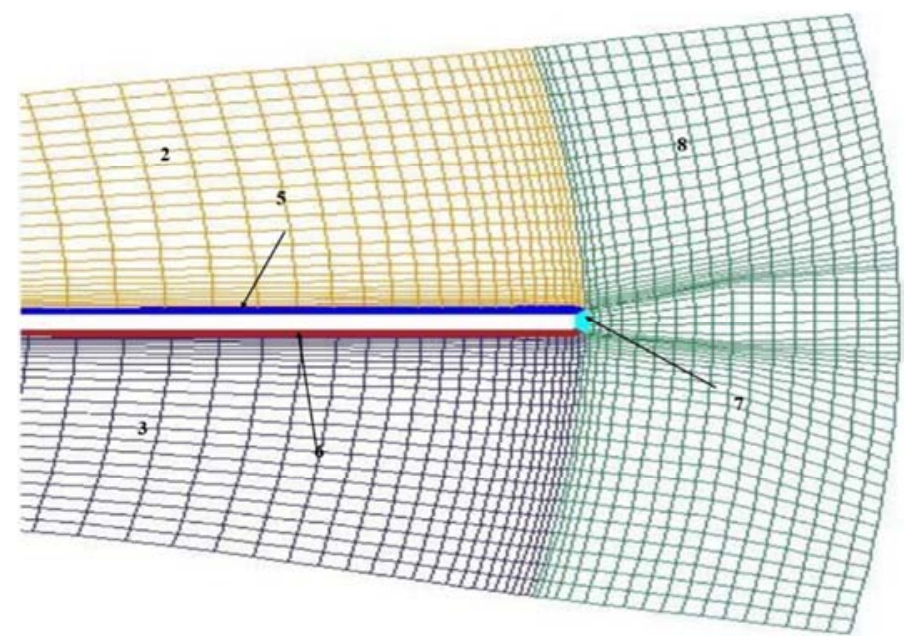

Figure 4. Passage grid block structure near trailing edge at blade mid span.

\subsection{Chamfered Tips}

In the present study, tip modifications are made to the above basic centrifugal impeller to investigate their effects on the flow. Tip chamfering is the removal of material from the blade tip. The details of the five configurations of chamfered tips studied are given below.

Two configurations of blade tips with chamfer on pressure surface, P1 and P2 are analysed. In case P1, the blade tip is cut in three directions, $5 \mathrm{~mm}$ along blade height, $20 \mathrm{~mm}$ along blade pressure surface away from trailing edge and $1 / 3^{\text {rd }}(1 \mathrm{~mm})$ of blade thickness along blade thickness direction. In case $\mathrm{P} 2$, the blade tip is chamfered with $2 / 3^{\text {rd }}(2$ $\mathrm{mm})$ of blade thickness along blade thickness direction and the other two dimensions of chamfer are same as those of P1 configuration. Two geometries of blade tip with chamfer on suction surface, S1 and S2 are analyzed. In case S1, the blade tip is cut in three directions, $5 \mathrm{~mm}$ along blade height, $20 \mathrm{~mm}$ along blade suction surface away from trailing edge and $1 / 3^{\text {rd }}$ ( $1 \mathrm{~mm})$ of blade thickness along blade thickness direction. In case $\mathrm{S} 2$, the blade tip is chamfered with $2 / 3^{\text {rd }}(2 \mathrm{~mm})$ of blade thickness along the blade thickness direction and the other two dimensions are same as those of $\mathrm{S} 1$ configuration. For PS1, the blade tip is cut on both pressure and suction surfaces. On pressure surface the blade tip is cut in three directions, 5 $\mathrm{mm}$ along blade height, $20 \mathrm{~mm}$ along blade pressure surface away from trailing edge and $1 / 3^{\text {rd }}(1 \mathrm{~mm})$ of blade thickness along blade thickness direction. The blade tip is also cut on suction surface in three directions, $5 \mathrm{~mm}$ along blade height, $20 \mathrm{~mm}$ along blade suction surface away from trailing edge and $1 / 3^{\text {rd }}(1 \mathrm{~mm})$ of blade thickness along blade thickness direction. The length of chamfer is kept constant at $20 \mathrm{~mm}$ for all tip configurations. This corresponds to a radius ratio of 0.92 . The impeller blade height is constant from radius ratio of 0.92 to 1 (impeller tip). The tip clearance flows are strong in this region. Figure 5 shows the impeller blade with different tip configurations: basic (without chamfer), P1, P2, PS1, S1 and S2.

\section{Results and Discussion}

The results obtained from the computational study are presented and discussed in the following sections. For the sake of brevity, computational results for the case of design 
flow coefficient of 0.42 and nominal tip clearance of $2 \%$ are presented and discussed in detail. However the values of the total pressure coefficient for the ninety cases (six configurations, five flow coefficients and three tip clearances) are compared to arrive at the best configuration.

\subsection{Grid Independency Studies}

In order to study the effect of grid independency, the grid size in the domain is increased till the effect of grid on the results is very small. The grid dependency studies are carried out for the impeller with $2 \%$ tip clearance at the design flow coefficient of 0.42 . Coarse grid of 129,522 elements, medium grid of 426,201 elements (grid is increased by 1.5 times in all three directions), 527,201 elements (medium grid with increased grid in tip clearance region), 727,268 elements (grid is increased by 1.8 times in all three directions), and 982,400 (medium grid with very fine grid in tip clearance region) are used. The results of grid independency studies are shown in Table 2. From the results, it is observed that the computed values for grid of 527,201 elements are close to the computed values with grids of 727,268 and 982,400 elements. As the time taken is also moderate, grid of 527,201 elements is taken as the optimum grid. Hence all computations are carried out with the grid of 527,201 elements. The grid independency studies clearly demonstrate that any changes in the performance of the impeller are not due to grid inadequacy but due to chamfer only.

Table 2. Results of grid independency study at $\phi=0.42$ and $\tau=2 \%$.

\begin{tabular}{llllllll}
\hline Grid Size & $\overline{\bar{\psi}}_{\text {o }}$ & \% Change & \% Change* & $\overline{\bar{\psi}}_{\mathrm{S}}$ & \% Change $^{+}$ & \% Change* $^{*}$ Computation Time in Hours $^{*}$ \\
\hline 129,522 & 1.5827 & - & - & 0.7612 & - & - & 0.17 \\
426,201 & 1.5932 & 0.67 & 0.67 & 0.7625 & 0.17 & 0.17 \\
527,201 & 1.5968 & 0.89 & 0.23 & 0.7651 & 0.51 & 0.34 \\
727,268 & 1.5973 & 0.92 & 0.03 & 0.7660 & 0.63 & 0.12 \\
982,400 & 1.5975 & 0.93 & 0.01 & 0.7654 & 0.56 & -0.08 \\
\hline
\end{tabular}

${ }^{+}$The percentage changes are with respect to the smallest grid size. ${ }^{*}$ The percentage changes are with respect to the previous grid size.

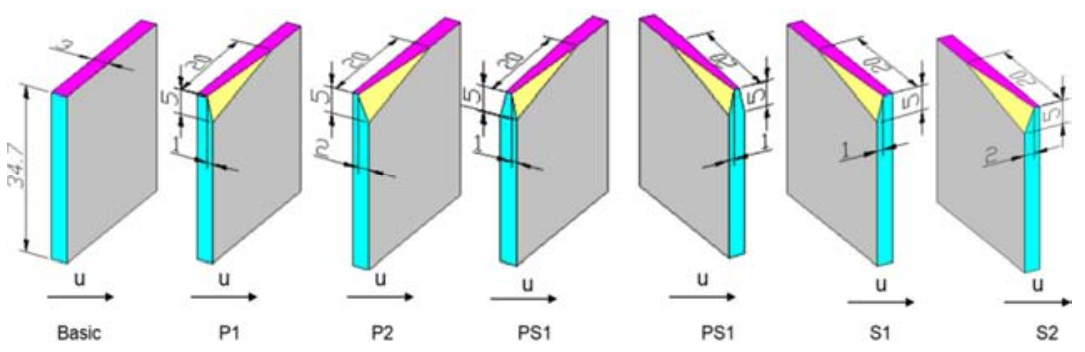

Figure 5. Details of blades with chamfered tips (All dimensions in $\mathrm{mm}$ )

\subsection{Effect of Chamfered Tips on the Performance of Centrifugal Compressor}

The centrifugal impeller blade is chamfered at its tip and the effect of chamfer on flow behavior is analysed. Centrifugal impeller with five chamfered tip configurations at five flow coefficients $0.28,0.34,0.42,0.48$ and 0.52 are analysed for three tip clearances, i.e. $1 \%, 2 \%$ and $5 \%$ of exit blade height. The variation in flow parameters of impellers with five tip configurations is compared with the parameters of basic impeller without chamfer. The effects of blade tip chamfer provided on pressure and suction surfaces on the flow field are analysed. For the sake of brevity, computational results for the case of design flow coefficient of 0.42 and nominal tip clearance of $2 \%$ are presented and discussed in detail. However the values of the total pressure coefficient for the ninety cases (six configurations, five flow coefficients and three tip clearances) are compared to arrive at the best configuration.

The performance curves drawn from mass averaged total pressure coefficients for the impellers with six tip configurations with $2 \%$ tip clearance are shown in Figure 6. The total pressure coefficient is maximum at the flow coefficient of 0.34 . The order of variation in total pressure coefficient for various configurations is clearly shown in the inset. The improvement in the performance is observed with suction surface chamfer, but decrease in performance is observed with pressure surface chamfer.

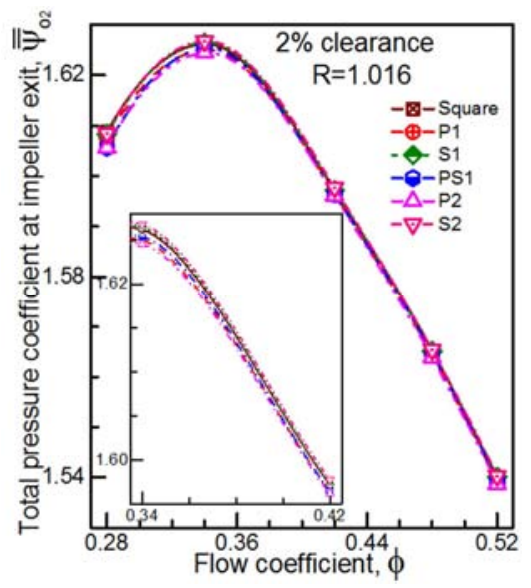

Figure 6. Mass averaged total pressure coefficient across the exit of the impeller with different blade tip chamfers at $R=1.016, \tau=2 \%$.

At lower flow coefficients, the performance of impeller with S1 tip is slightly lower than the performance curve of the 
impeller with square tip. At higher flow coefficients, the performance of impeller with S1 tip is slightly higher than the performance curve of the impeller with square tip. The mass averaged total pressure coefficient difference for the impellers with P1 and PS1 are less than the mass averaged total pressure coefficient difference of the impeller with square tip.

The performance curves drawn from mass averaged static pressure rise coefficients (difference between exit and inlet static pressures) for the impellers with six tip configurations with $2 \%$ tip clearance are shown in Figure 7 . The impeller with S2 tip indicates highest performance. The impeller with P2 tip shows poor performance whereas impeller with S1 tip gives slightly improved performance. The performance of impeller with PS1 and P1 tips is same as the performance of with the impeller with square tip. The order of variation in static pressure rise coefficient for various configurations is clearly shown in the inset.

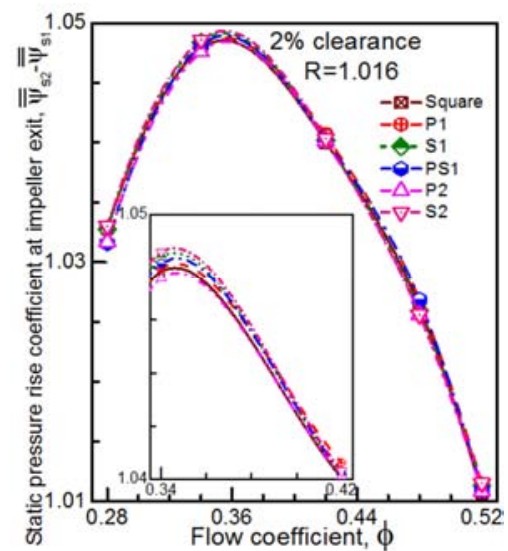

Figure 7. Mass averaged static pressure rise coefficient across the exit of the impeller with different blade tip chamfers at $R=1.016, \tau=2 \%$.

The effect of chamfered tips on the flow field is presented in the following sections. Contours of total and static pressure coefficients, velocity vectors and relative flow angles at a radius ratio of 0.984 (inside the impeller passage near the tip) for the six tip configurations with a tip clearance of $2 \%$ at the flow coefficient of 0.42 are presented and discussed.

\subsection{Effect of Chamfered Tips on the Flow Field of Centrifugal Compressor}

\subsubsection{Contours of Total Pressure Coefficients}

For the impeller with $2 \%$ clearance at flow coefficient 0.42 , the total pressure coefficient contours at a radial ratio of 0.984 , just before the trailing edge of the impeller is shown in Figure 8. The total pressure coefficient is reducing from blade tip to casing on the pressure side of the blade due to the boundary layer effect on stationary casing. In the tip gap the total pressure coefficient near the casing is very low.

On the suction side of the blade, the total pressure coefficient increases from low total pressure coefficient at casing to the tip of the blade. Total pressure coefficient of the fluid is reduced in the tip gap and this low total pressure fluid is mixing with the fluid in the suction side of the blade. There is very little change observed in the total pressure coefficient contours for impellers of six tip configurations.

\subsubsection{Contours of Static Pressure Coefficients}
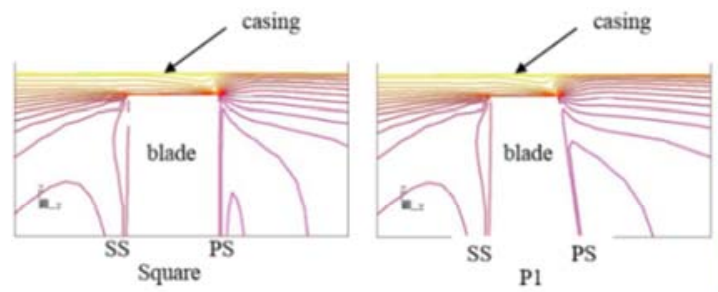

2.1322 .00

1.9525 .00

$1.7715 \cdot 00$

1.5915 .00
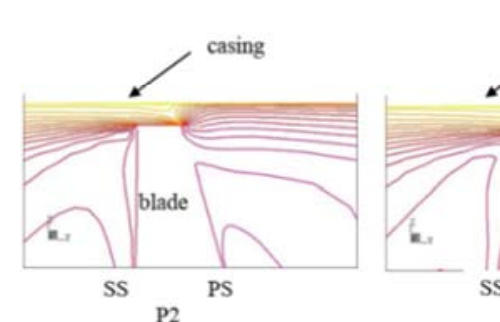

P1

411500

$1.050 \mathrm{E}+00$

$8.7055-0$

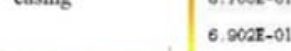

5. $099 \mathrm{E}-01$

$3.296 \mathrm{E}-01$

$1.494 \mathrm{E}-01$

$-3.087 \mathrm{E}-02$

$-2.111 \mathrm{~F}-01$

$-3.914 \mathrm{E}-01$

$-5.717 \mathrm{E}-01$
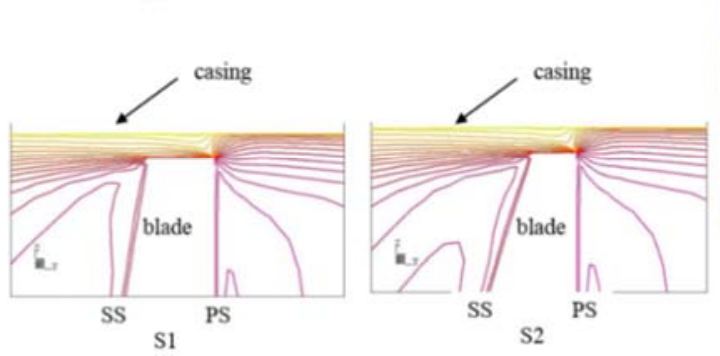

$-7.520 \mathrm{E}-0$

$-9.323 \mathrm{E}-01$

$-1.112 \mathrm{E}, 00$

$-1.2925 .00$

Figure 8. Contours of total pressure coefficient at radial location $R=0.984$, $\tau=2 \%, \phi=0.42$.
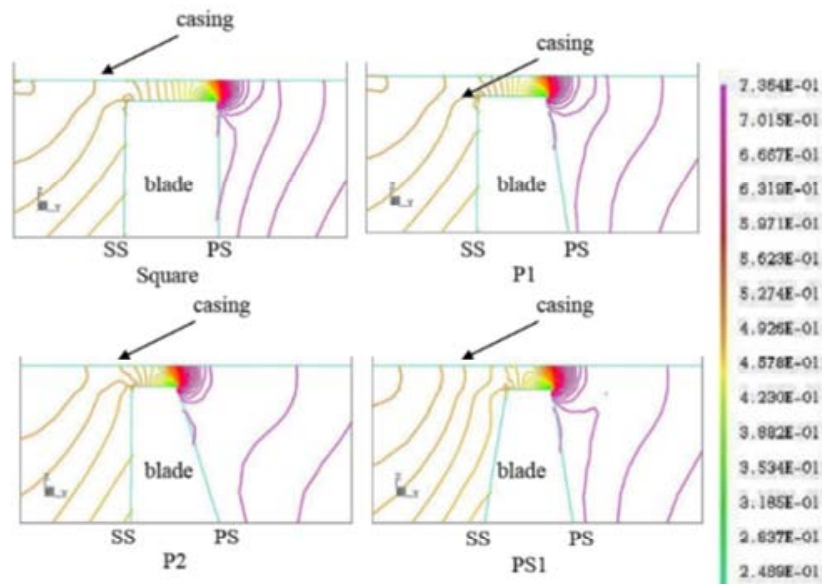

8., $623 \mathrm{E}-01$

5.274E-01

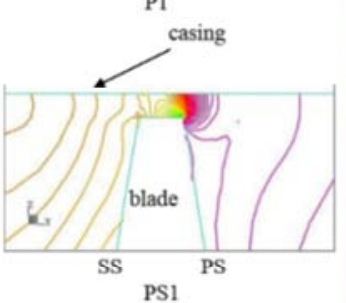

4.9265-01

4. $578 x-01$

4. 230 - 01

3. $802 x-01$

3.534 -01

3. 1 125E-01

2. $8375-01$
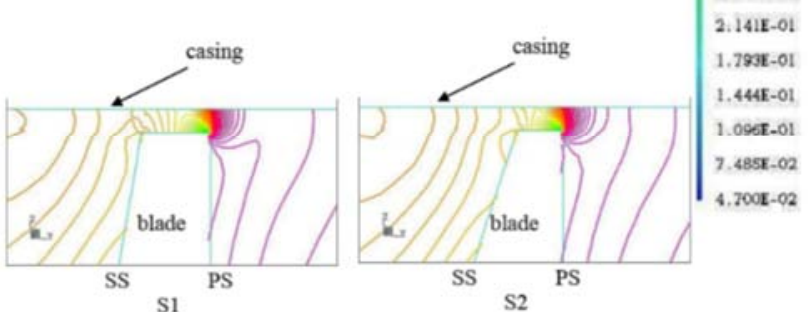

Figure 9. Contours of static pressure coefficient at radial location $R=0.984$, $\tau=2 \%, \phi=0.42$.

For the impeller with $2 \%$ clearance at flow coefficient 0.42 , the static pressure coefficient contours at a radial radius of 
0.984, just before the trailing edge of the impeller are shown in Figure 9. The static pressure coefficient on the pressure side of the blade is high and on the suction side of the blade is low indicating the blade loading. In the tip gap near the pressure side corner, recirculation region with low static pressure coefficient is observed. There is not much change seen in the static pressure coefficient contours for impellers of six tip configurations at this radial plane.

\subsubsection{Contours of Relative Flow Angles}
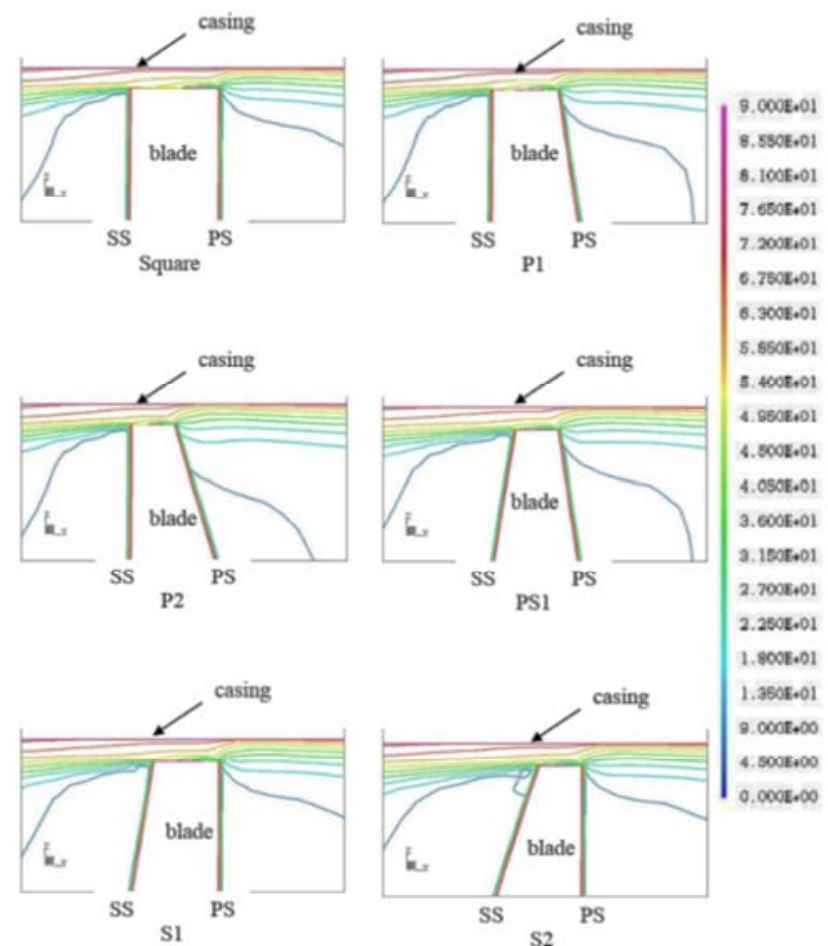

Figure 10. Contours of relative flow angle at radial location $R=0.984$, $\tau=2 \%, \phi=0.42$.

The relative flow angle contours at a radial radius of 0.984 just before the trailing edge of the impeller, for the impeller with $2 \%$ clearance at flow coefficient 0.42 is shown in Figure 10. The angle between relative velocity and meridional velocity is taken as relative flow angle. The contours are plotted for the impellers with six tip configurations. The tip clearance region and a part of the blade height are shown in close up to show the details in the tip clearance region in the plane. All the contours are plotted to the single global scale. The relative flow angle contours of the impeller with square tip shows increase in relative flow angle on the pressure side of the blade from blade tip to casing. In the tip clearance space, recirculation region is observed near the pressure side on the blade tip. The sharp turning of the fluid from the pressure surface of the blade into the tip gap is forming the recirculation region on the blade near pressure surface in the tip gap. The relative flow angle near the casing is high as the casing is stationary. On the suction side of the blade the relative flow angle is decreasing from the casing to the tip of the blade. For the impeller with P1 tip, the chamfer on pressure surface is allowing the smooth turning of the flow in the tip gap. The relative flow angles are increasing on pressure surface of the blade before the tip.

The size of the recirculation region is reduced. For the impeller with P2 tip, more chamfer on pressure surface is causing the fluid to turn smoothly into the tip gap. The relative flow angles are increasing on pressure surface of the blade much before the tip. The size of the recirculation region is further reduced.

For the impeller with PS1 tip, chamfer on pressure surface of the blade is causing the relative flow angles to increase on pressure surface of the blade before the tip. The chamfer on suction surface of the blade is turning the flow up into the tip gap and opposing the tip clearance flow. The recirculation region is occupying the entire tip width. For the impeller with $\mathrm{S} 1$ tip, the relative flow angles are increasing from the tip to casing as in the case of impeller with square tip. The recirculation region size is increased.

For the impeller with S2 tip, the relative flow angles are increasing from the tip as in the case of impellers with square tip and S1 tip. Recirculation region is occupying the entire width of the tip.

The relative flow angles are increasing on pressure surface before tip for pressure surface chamfer. The recirculation region size on the blade tip near pressure side is reduced with increase in pressure surface chamfer dimension in thickness direction. For the impellers with suction surface chamfer the relative flow angles are increasing on pressure surface from tip to casing same as in the case of impeller with square tip. The recirculation region size increases with increase in suction surface chamfer dimension in thickness direction.

\subsubsection{Relative Velocity Vectors}

For the impeller with $2 \%$ clearance at flow coefficient 0.42 , the relative velocity vector components on the plane at a radial radius of 0.984 just before the trailing edge of the impeller are shown in Figure 11. The relative velocity vector components on the plane for the impeller with square tip are turned on the blade pressure surface towards the tip gap direction. The relative velocity on the casing is high. From a very low velocity on tip of the blade, the relative velocity increases towards the casing which can be attributed to the relative motion of the outer casing with respect to fluid domain in the direction of leakage flow. On the suction side of the blade, the tip leakage flow is mixing with the main flow on the suction side of the blade. For the impeller with P1 tip, the chamfer on pressure surface of the blade is turning the velocity vectors smoothly towards the tip gap. In the tip gap the velocity increases from the blade tip to the casing.

For the impeller with P2 tip, the flow is turning far smoothly into the tip gap on the pressure surface of the blade. For the impeller with PS1 tip, due to the pressure surface chamfer the flow is turned into the tip gap smoothly and due to the suction surface chamfer the flow on the suction surface is turned towards the tip gap obstructing the tip leakage flow. The shear layer in the tip gap is diffusing at a faster rate on the suction side of the blade.

For the impellers with S1 and S2 tip, the flow on pressure 
surface is turning towards the tip gap vertically, and the chamfer on suction surface is turning the flow in the tip gap direction opposing the tip leakage flow. With increase in suction surface chamfer dimension, the flow is turned more towards the tip gap and offering more resistance to the tip leakage flow. Hence tip leakage flows are reduced and the impeller performance is improved. The diffusion of the shear layer is at faster rate with chamfer on suction surface.
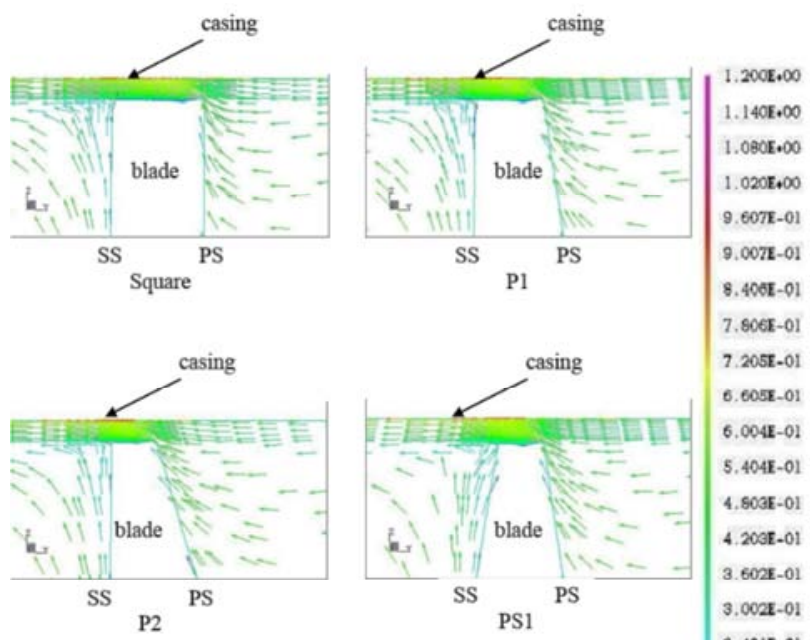

7. $205 \mathrm{E}-01$
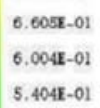

4.50aE-01

4. $203 \mathrm{E}-01$
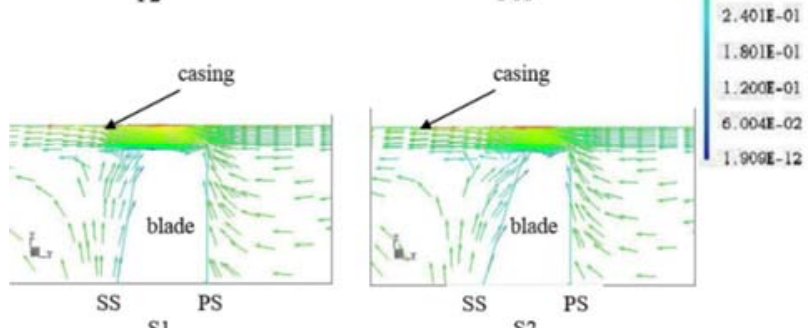

Figure 11. Velocity vectors at radial location $R=0.984, \tau=2 \%, \phi=0.42$

\subsection{Effect of Chamfered Tips on the Mass Averaged Total Pressure Coefficient at the Impeller Exit}

The variation of mass averaged total pressure coefficient with the tip clearance at the radius ratio of 1.106 at the five flow coefficients is shown in Figure 12. Although the changes in the value of total pressure coefficient for different tip configurations is very small but still visible. The decrease in total pressure coefficient is as follows. S2, S1, Basic, P1, PS1 and P2. The maximum and minimum values of total pressure coefficients in terms of percentage of total pressure coefficient for the basic configuration are presented in Table 3. The overall maximum and minimum total pressure coefficients occur for S2 tip and P2 tip respectively for 5\% tip clearance at the flow coefficient of 0.52 and 0.34 respectively. The values are $0.18 \%$ and $-0.23 \%$ of the corresponding total pressure coefficient for impeller with square tip. The total pressure coefficient decreases linearly with tip clearance. However the decrease is slightly different for different flow coefficients and different tip configurations

In the present investigation the chamfer angle is relatively large compared to the chamfer angle used by Tallman [17]. He studied the effect of chamfer angle on the turbine tip clearance flows and found that a chamfer angle less than $4^{\circ}$ may be optimum. Perhaps with the reduced chamfer angle, the benefits of blade tip chamfer on the performance and flow field in centrifugal impellers may be higher.

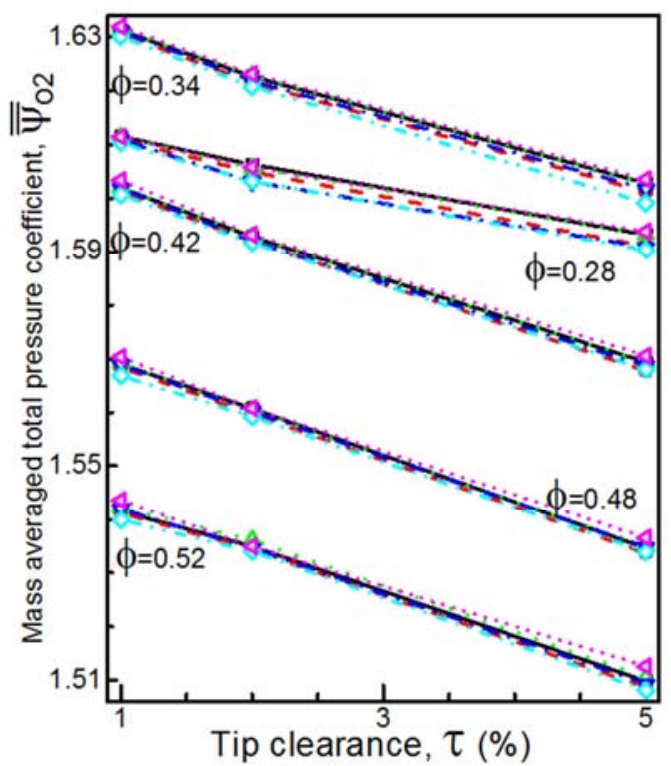

Figure 12. Variation of mass averaged total pressure coefficient with tip clearance.

\subsection{Effect of Chamfered Tips on the Relative tip Clearance Sensitivity}

The mass averaged total pressure coefficient presented in Figure 12 is used to calculate relative sensitivity coefficient with tip clearance at different flow coefficients for the six configurations. Relative sensitivity coefficient is defined as follows:

$$
\frac{\left[\bar{\psi}_{\mathrm{O} 2}(\tau=1 \%)-\bar{\psi}_{\mathrm{O} 2}(\tau=5 \%)\right]_{\text {Config }}}{\left[\bar{\psi}_{\mathrm{O} 2}(\tau=1 \%)-\overline{\bar{\psi}}_{\mathrm{O} 2}(\tau=5 \%)\right]_{\text {Basic }}}
$$

The variation of relative sensitivity coefficient with flow coefficient for the five chamfered configurations is shown in Figure 13. A horizontal line at a value of one is also shown in the figure. Curves below this line means sensitivity with tip clearance is lower than that for the basic configuration. Curves above this line means sensitivity with tip clearance is more than that for the basic configuration. Configurations S1 and S2 show lower relative sensitivity coefficient with Configuration S2 lowest. Other three configurations, namely $\mathrm{P} 1, \mathrm{P} 2$ and PS1 have relative sensitivity coefficient more than one, implying that these configurations are more susceptible to increased tip clearance compared with the basic configuration, hence not desirable.

Table 3. Percentage change in overall maximum and minimum values of total pressure coefficients.

\begin{tabular}{lllll}
\hline & Configuration & $\boldsymbol{\tau} \mathbf{( \% )}$ & $\phi$ & $\%$ Change \\
\hline Overall maximum value & $\mathrm{S} 2$ & 5 & 0.52 & 0.18 \\
Overall Minimum value & $\mathrm{P} 2$ & 5 & 0.34 & -0.23 \\
\hline
\end{tabular}




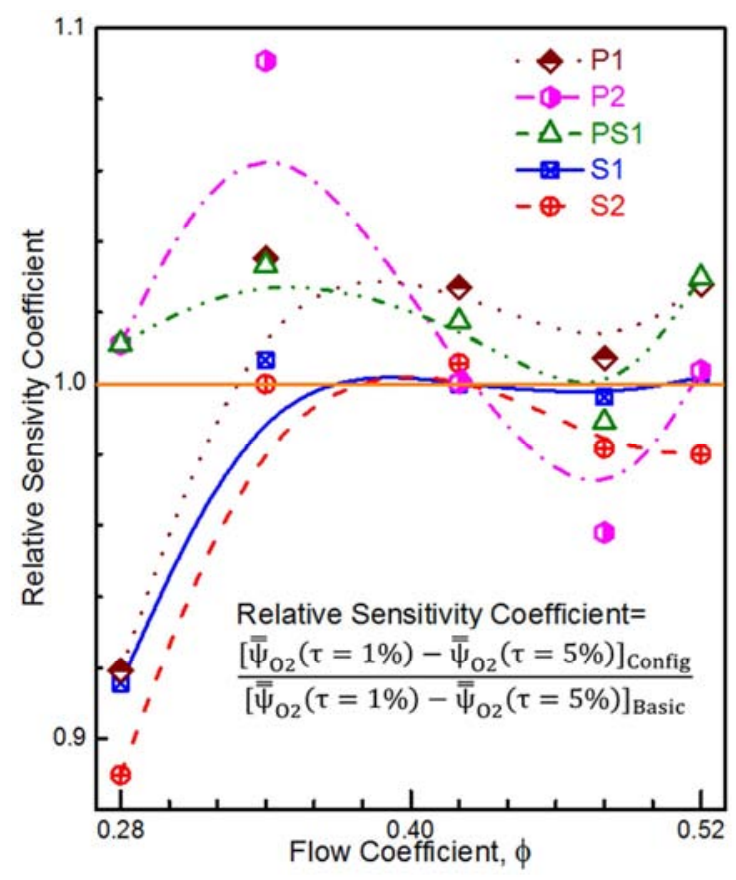

Figure 13. Variation of relative sensitivity coefficient with flow coefficient.

\section{Conclusions}

The effect of chamfered tips on the performance of a centrifugal compressor is investigated using commercial CFD software. Comprehensive grid independency studies were carried out to establish that the changes in the performance of the impeller are not due to inadequacy of the grid but due to the tip chamfer only. Two configurations with chamfers on the suction surface, two configurations with chamfers on the pressure surface and one configuration with chamfers on both the suction and pressure surfaces of the impeller tip are investigated. Computations are carried out for the above five configurations and compared with the computational results for the basic configuration without tip chamfer for five flow coefficients. The computations are carried out with optimized multiblock grids for these six configurations at five flow coefficients, namely 0.28 and 0.34 (below design flow coefficient), 0.42 (design flow coefficient) and 0.48 and 0.52 (above design flow coefficient) and at three values of tip clearance, viz., $1 \%$ (small value), $2 \%$ (nominal value) and 5\% (large value) of the blade exit height. From the computational investigations, it is found that the mass averaged total and static pressure coefficients from inlet to outlet of the passage decrease with increase in tip clearance. At higher flow coefficients, the pressure drop is predominant due to the increased effect of tip clearance. The passage wake grows with increase in clearance and the position of the wake is moved away from the suction surface near casing towards mid passage. With increase in clearance, the extent of tip clearance effects along the spanwise direction increases.

The impeller with chamfer on suction surface shows performance improvement. A decrease in the chamfer dimension on suction surface results in considerable performance improvement. A maximum percentage of $0.18 \%$ improvement in total pressure coefficient is obtained at 5\% tip clearance and a flow coefficient of 0.52 for this configuration, $\mathrm{S} 2$. This configuration has also shown minimum sensitivity for tip clearance effects. The possible reason is due to increased contraction coefficient of the leakage flow. Blade loading is affected very little by the suction surface chamfer. It is also postulated that further decrease in tip chamfer on the suction surface will be more beneficial. Pressure surface chamfer deteriorates the performance of the impeller. An increase in the chamfer dimension on pressure surface results in poor performance.

\section{Nomenclature}

C

$\mathrm{m}$

$\mathrm{p}$

$\mathrm{r}$

$\mathrm{R}$

$\mathrm{u}$

W

$\mathrm{X}$

$\mathrm{X}$

$\phi$

$\tau$

$\rho$

$\psi_{\mathrm{o}}$

$\psi_{\mathrm{s}}$

Subscripts

1

2

a

Absolute velocity $(\mathrm{m} / \mathrm{s})$

Non-dimensional meridional distance, $\mathrm{m}=0$ at $\mathrm{LE}, \mathrm{m}=1$ at $\mathrm{TE}$

Pressure $\left(\mathrm{N} / \mathrm{m}^{2}\right)$

Radius (m)

Non-dimensional radius $=\mathrm{r} / \mathrm{r}_{2}(\mathrm{R}=1$ at tip $)$

Blade speed (m/s)

Relative velocity $(\mathrm{m} / \mathrm{s})$

Axial distance (m)

Non-dimensional axial distance $=\mathrm{x} / \mathrm{b}(\mathrm{X}=0$ at hub, $\mathrm{X}=1$ at casing $)$

Flow coefficient $=\mathrm{C}_{2 \mathrm{~m}} / \mathrm{U}_{2}$

Tip clearance expressed as percentage of exit blade height

Density $\left(\mathrm{kg} / \mathrm{m}^{3}\right)$

Total pressure coefficient $=2 \mathrm{P}_{\mathrm{O}} / \rho \mathrm{U}_{2}^{2}$

Static pressure coefficient $=2 \mathrm{P}_{\mathrm{S}} / \rho \mathrm{U}_{2}^{2}$

inlet

outlet

atmospheric 


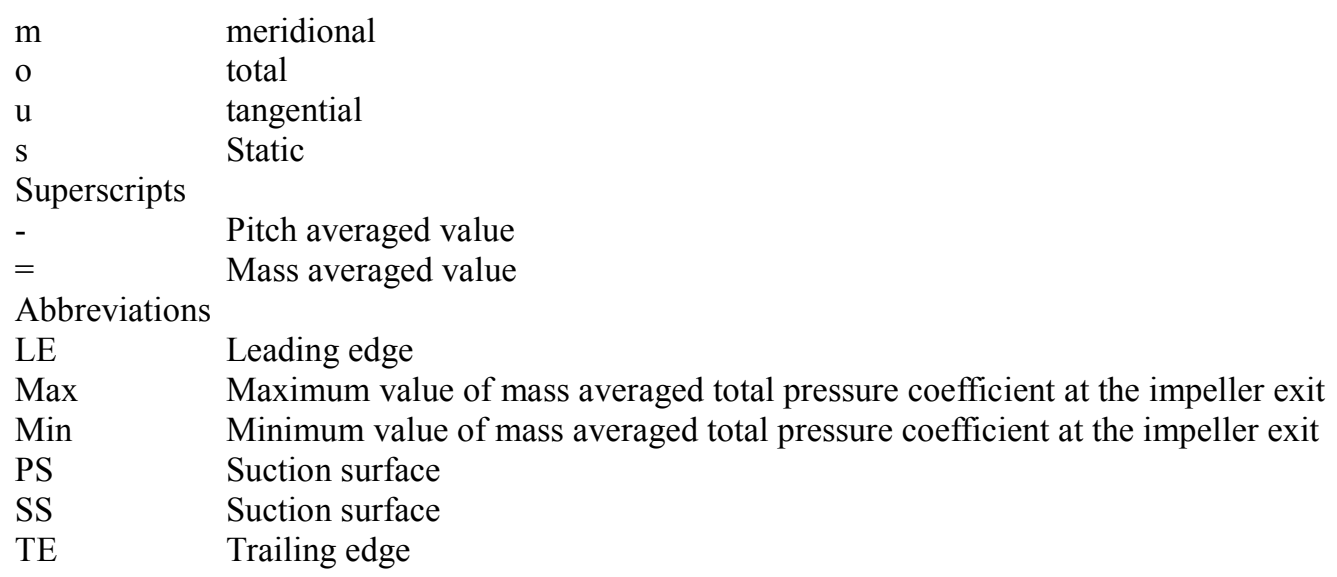

\section{Acknowledgements}

The research reported in this paper was sponsored by Council for Scientific and Industrial Research (CSIR). The second author was supported by AICTE and Osmania University under QIP scheme. The responsibility for the contents lies solely with its authors.

\section{References}

[1] Johnson M. W. and J. Moore. Development of wake flow in centrifugal compressors. ASME Jl. of Engg. for Power, 1980 102 (2), 382-390 https://doi.org/10.1115/1.3230265.

[2] Senoo Y. Pressure losses and flow field distortion induced by tip clearance of centrifugal and axial compressors, JSME Int. Jl. 198030 (261) 375-385 https://doi.org/10.1299/jsme1987.30.375.

[3] Sitaram N. and Sridhara T. N. Recent investigations on tip clearance flows in centrifugal compressors, Int. Jl. of Turbo and Jet Engines, 2000, 17 (1) 65-78 10.1515/TJJ.2000.17.1.65.

[4] Hayami H. Research and development of a transonic turbo compressor, in: Turbomachinery Fluid Dynamics and Heat Transfer, Ch. Hah (Ed.), 1997 Marcel Dekker Inc., New York, 63-82.

[5] Pampreen R. C. Small turbomachinery compressor and fan aerodynamics, ASME Jl. of Engg. for Power, 1973, 95 (3) pp. 205-212 https://doi.org/10.1115/1.3445730.

[6] Sitaram N. and Pandey B. Tip clearance effects in a centrifugal compressor rotor, $\mathrm{Jl}$. of the Aero. Society of India, 1990, 42 (2), 309-315.

[7] Farge T. Z., Johnson M. W. and Maksoud T. M. A. 1989 Tip leakage loss in a centrifugal impeller, ASME Jl. of Turbomach., 1989, 111 (2) 244-249.

[8] Senoo Y and Ishida M. Pressure loss due to the tip clearance of impeller blades in centrifugal and axial blowers, $A S M E \mathrm{Jl}$. of Engg. for Gas Turbines and Power, 1986, 108 (1), 32-37.

[9] Ubaldi M., Zunino P. and Cattanei A. Relative flow and turbulence measurements downstream of a backward centrifugal impeller, ASME Jl. of Turbomach., 1993, 115, pp.
543-551 https://doi.org/10.1115/1.2929288.

[10] Hathaway M. D. and Wood J. R. Application of a multi-block CFD code to investigate the impact of geometry modeling on centrifugal compressor flow field predictions, ASME Jl. of $\begin{array}{llll}\text { Turbomach., } & 1997, & 119 & \text { (4) }\end{array}$ https://doi.org/10.1115/1.2841193.

[11] Ishida M., Ueki H. and Senoo Y. Effect of blade tip configuration on tip clearance loss of a centrifugal impeller, ASME Jl. of Turbomach., 1990, 112 (1) 14-18, https://doi.org/10.1115/1.2927412.

[12] Sitaram N. and Swamy S. M. Performance improvement of a centrifugal compressor by passive means, International Journal of Rotating Machinery, Volume 2012, Article ID 727259, 9 pages, doi: 10.1155/2012/727259.

[13] Senthil S. and Sitaram N. Performance improvement of a centrifugal compressor by means of squealer tips, Proc. of the $4^{\text {th }} I C P F$, 2002, Beijing, China, 26-29.

[14] Da Soghe Riccardo, Bianchini Cosimo, Tommaso Rubino Dante and Toni Lorenzo. Effects of impeller squealer tip on centrifugal compressor performance, ASME Jl. of Engg. for Gas Turbines and Power, V. 139, pp. 032603-1 to 032603-7 https://doi.org/10.1115/1.4034541.

[15] Jung Y., Choi M., Park J. and Baek J. Effects of recessed blade tips on the performance and flow field in a centrifugal compressor, Proc. Inst. Mech. Eng., 2012, Part A Journal of Power and Energy, 227 (2) 157-166 doi: $10.1177 / 0957650912465278$.

[16] Mahajan Ashvin, Baert Lieven, Leborgne Michaël, Lonfils Timothée, Parwatha I. Gede and Timoshadchenko Denis. Numerical investigation of impeller tip tailoring and its impact on aerodynamic design of a centrifugal compressor's impeller, ASME Paper No. GT2014-25641, V02DT42A014, ASME Turbo Expo 2014: Turbine Technical Conference and Exposition, Volume 2D: Turbomachinery, Düsseldorf, Germany, 201412 pages, doi: 10.1115/GT2014-25641.

[17] Tallman J. A. A computational study of tip desensitization in axial flow turbines, Part 2: Turbine Rotor Simulations with Modified Tip Shapes, ASME Paper GT-2004-53919, ASME Turbo Expo 2004: Power for Land, Sea, and Air, Vienna, Austria, 200412 pages, doi: 10.1115/GT2004-53919. 